\title{
Temporal preparation facilitates perceptual identification of letters
}

\author{
BETTINA RoLKE \\ University of Tübingen, Tübingen, Germany
}

\begin{abstract}
Recent evidence has suggested that perceptual processing of single stimulus features improves when participants are temporally prepared for the occurrence of the stimuli. This study was conducted to investigate whether the benefit of temporal preparation generalizes to perceptual identification of more complex stimuli, such as letters. In three experiments, participants discriminated masked letters under high- and low-temporal-preparation conditions. Visual discrimination performance in all experiments improved when the participants were temporally prepared. Therefore, the present results support the notion that perception benefits from temporal preparation not only at the feature level, but also at subsequent levels at which feature information is integrated.
\end{abstract}

Participants respond especially quickly to a stimulus when the temporal occurrence of this stimulus can be anticipated (Woodrow, 1914). This benefit of temporal preparation on reaction time (RT) has been repeatedly demonstrated (Bevan, Hardesty, \& Avant, 1965; Klemmer, 1956; Niemi \& Näätänen, 1981; Teichner, 1954) and been shown to be a robust phenomenon. For example, the temporal preparation effect is obtained with visual as well as with auditory stimuli (Niemi \& Lehtonen, 1982; Sanders \& Wertheim, 1973), and also for cross-modal stimulus arrangements (Drazin, 1961; Müller-Gethmann, Ulrich, \& Rinkenauer, 2003; Rodway, 2005). In addition, this effect is observed for simple as well as for choice responses (see, e.g., Simon \& Slaviero, 1975) and thus is independent of particular response requirements. According to Niemi and Näätänen (1981), a warning signal reduces uncertainty about when an imperative stimulus will occur, which in turn promotes the temporal preparation of the response.

To improve understanding of the temporal preparation effect, several studies have aimed to localize the effect within the processing stream from perceptual input to the corresponding response (for reviews, see Hackley \& Valle-Inclán, 2003; Müller-Gethmann et al., 2003). The results of different experimental approaches, however, have revealed different loci of the temporal preparation effect. Specifically, some authors (e.g., Los, Knol, \& Boers, 2001, Los \& Van Den Heuvel, 2001; Sanders, 1998) and studies employing the additive-factor method (Sternberg, 2001) have argued that temporal preparation does not operate at early perceptual stages (e.g., Frowein \& Sanders, 1978; Niemi, 1979; Niemi \& Lehtonen, 1982; Raab, Fehrer, \& Hershenson, 1961), but instead shortens the duration of late motor processes (Sanders, 1980a, 1998; Spijkers, 1990).
This assumption seems to be supported by studies in which the effects of temporal preparation on the correlates of motor processes have been assessed. For example, studies of this type have investigated such measures as response force (Mattes \& Ulrich, 1997), reflex amplitude (Brunia \& van Boxtel, 2000), transcranially evoked motoric potentials (Hasbroucq, Kaneko, Akamatsu, \& Possamaï, 1999; Tandonnet, Burle, Vidal, \& Hasbroucq, 2003, 2006), and the contingent negative variation (Loveless, 1973; Van der Lubbe, Los, Jaśkowski, \& Verleger, 2004). All of these studies concluded that temporal preparation affects motor processes.

More recent studies, however, have challenged the notion that temporal preparation operates exclusively or primarily at a late motoric level. The first line of evidence for an earlier locus of the temporal preparation effect emerged from chronophysiological studies (Hackley, Schankin, Wohlschläger, \& Wascher, 2007; Hackley \& Valle-Inclán, 1998, 1999; Müller-Gethmann et al., 2003; Smulders, 1993 ) employing lateralized readiness potentials to bisect RTs into early and late portions. Contrary to the prevailing view, the results of these studies showed that a reduction of temporal uncertainty shortens the early but not the late portion of RT. Hence, these studies support the conclusion that temporal preparation facilitates the speed of premotoric processes. ${ }^{1}$

A second line of evidence for a premotoric locus of the temporal preparation effect was introduced in a recent study by Bausenhart, Rolke, Hackley, and Ulrich (2006). The authors employed the psychological refractory period (PRP) paradigm (Pashler \& Johnston, 1998) and used the effect propagation property (Miller \& Reynolds, 2003) of the PRP, which allows for tracing effects back to motoric and premotoric processing stages. The PRP paradigm requires that participants perform two successive yet tempo-

B. Rolke, bettina.rolke@uni-tuebingen.de 
rally overlapping RT tasks, while temporal preparation for the first task is manipulated. Consistent with the prediction of a premotoric locus of temporal preparation, the authors found that the effect of temporal uncertainty propagated completely from the first to the second task. On this basis, they concluded that the speed of early processing levels is affected by temporal preparation.

Although these two lines of evidence strongly support the notion that the temporal preparation effect results from premotoric facilitation, these studies cannot differentiate between the perceptual and central influences of temporal preparation on stimulus processing. The question of whether temporal preparation exerts an influence on the perceptual processing stage has previously been investigated in psychophysical studies. Whereas there is convincing evidence for a benefit of temporal preparation on perceptual processing in the auditory modality (Bausenhart, Rolke, \& Ulrich, 2007; Howarth \& Treisman, 1961; Loveless, 1975; M. Treisman \& Howarth, 1959), relatively few studies have investigated the influence of temporal preparation on perceptual performance within the visual modality. These studies employed signal detection tasks. For example, Lowe (1967) asked his participants to detect a briefly presented circular light flash. Temporal uncertainty about the occurrence of the stimuli was varied via the duration of the observation interval, which was defined by tones, with longer intervals (greater uncertainty) resulting in a decrement in stimulus detectability. Lowe interpreted this result by assuming that observers are more likely to confuse signal activation with internal noise activation when temporal uncertainty is high. In addition, Klein and Kerr (1974) varied the interval between the warning signal and the to-be-detected stimulus (foreperiod) within a block of trials from 50 to $1,000 \mathrm{msec}$. Subsequent to the presentation of an auditory warning signal, detection performance of a masked visual signal (a cross) increased across foreperiods up to $500 \mathrm{msec}$ but then decreased once again. The authors argued that under this variable-foreperiod condition, the optimal foreperiod duration proved to be $500 \mathrm{msec}$. In sum, signal detection tasks have provided some evidence that temporal preparation can facilitate the perceptual detection of simple visual stimuli.

In a recent study, Rolke and Hofmann (2007) further investigated the question of whether temporal preparation affects stimulus processing at the perceptual level. To isolate the perceptual stimulus processing stage, the authors employed a backward-masking procedure (Breitmeyer, 1984; Turvey, 1973) and presented a random visual noise pattern shortly after the target presentation. This kind of masking is known to selectively influence perceptual processing (see, e.g., Bachmann \& Allik, 1976; Smith \& Wolfgang, 2004; Turvey, 1973). The participants' task was to judge whether a small spatial gap within the target stimulus, a Landolt square, was on either the right or the left side of this square. Temporal preparation for the occurrence of the target stimulus was manipulated by employing a blocked foreperiod paradigm. In this paradigm, foreperiod length (i.e., the temporal interval between the warning signal and the imperative response signal) remains constant within a block of trials, but varies across blocks. This approach typically reveals an increase of RTs when the foreperiod length becomes long (Niemi \& Näätänen, 1981). Theoretically, this increase in RTs is assumed to reflect increasing difficulty in estimating the temporal onset of the response signal (Klemmer, 1956). Hence, foreperiods that are especially long produce less temporal preparation. Since discrimination performance in the gap detection task of Rolke and Hofmann's study was impaired as the foreperiod length increased, they concluded that temporal preparation enhances processing at a perceptual level within the visual modality.

Although the psychophysical studies and Rolke and Hofmann's (2007) study showed that temporal preparation facilitates perceptual discrimination performance, the studies did not specify the locus of this effect within the perceptual processing system. Specifically, according to information processing models of spatial attention, perceptual processing comprises several stages, including preprocessing, feature extraction, feature integration, and identification of a complete stimulus (see Sanders, 1980b; A. M. Treisman \& Gelade, 1980), and each of these stages might or might not benefit from temporal preparation. Since the Landolt-square gap detection task used by Rolke and Hofmann required the processing of a single local stimulus feature, it seems likely that the benefit of temporal preparation there depended on this specific task need. Specifically, it has been shown that performance in this gap detection task mainly depends on the spatial resolution of the visual system. For example, Yeshurun and Carrasco (1999; see also Carrasco, Williams, \& Yeshurun, 2002) employed a visual spatial-cuing study and presented the targets at different eccentricities. In line with neurophysiological knowledge, Yeshurun and Carrasco obtained decreased gap detection performance with increasing eccentricity. More important, however, was the result that this eccentricity effect diminished in cued, as compared with neutral, trials. The authors concluded that spatial attention enhances the spatial resolution at the cued location. In further studies, Yeshurun and Levy (2003) and Yeshurun (2004) also employed the gap detection task, and they obtained evidence that attention intensifies the activity of parvocellular neurons at the attended location. Therefore, the gap detection task seems to be a suitable tool for investigating the spatial resolution of the visual system at an early perceptual processing stage.

The influence of spatial attention on visual perceptual processing is not restricted to changes in spatial resolution but also includes other, higher order perceptual processing stages. For example, this notion is supported by a study of Prinzmetal, Presti, and Posner (1986; see also Cohen \& Ivry, 1989). Prinzmetal et al. employed a spatial-cuing paradigm and investigated whether attention affects the integration of color and shape information. Their participants were less likely to incorrectly combine colors and letter shapes if attention was allocated to the stimulus location. Most important, however, attention still affected feature integration, even if the amount of feature information was controlled and did not differ between attentional conditions. Overall, in the context of visual 
spatial attention, attention has been found to selectively affect different stages of perceptual processing. Thus, it is unclear whether temporal preparation only affects the spatial processing of single stimulus attributes, or also affects performance at higher order perceptual processing stages, which do not necessarily require high spatial resolution.

The aims of the present study were to test this question and to investigate whether the influence of temporal preparation generalizes to the perception of higher order visual stimuli. In three experiments, participants were asked to identify masked letters. In contrast to the Landolt-square stimuli used in the study of Rolke and Hofmann (2007), which required only a local analysis of a small part of the stimulus, this task required the extraction of features, integration of single features, and identification of the integrated feature pattern (Marr, 1982; A. M. Treisman \& Gelade, 1980).

\section{EXPERIMENT 1}

As in the study of Rolke and Hofmann (2007), temporal preparation was manipulated by a blocked foreperiod paradigm. The task of the participants was to judge which of 10 possible letters was presented. These letter stimuli were chosen to prevent participants from basing their perceptual judgments on single stimulus attributes - for example, the presence or absence of one vertical line. To enable an adequate range of task difficulty, the targets were masked after three different time intervals $(16,32$, or $48 \mathrm{msec})$. This manipulation was also used as a control check to assess whether the participants correctly performed the task. The expectation was that perceptual discrimination performance would improve as target duration increased. To avoid speed strategies, participants were asked to withhold their responses until a response cue occurred. If temporal preparation influences the perceptual identification of letters, better discrimination performance for the short than for the long foreperiod should result.

\section{Method}

Participants. A group of 20 female participants voluntarily took part in this experiment (mean age $=25.1$ years). The participants had normal or corrected-to-normal vision, were mainly recruited from the Tübingen student pool, and received course credit or a payment $(€ 7 / h)$.
Stimuli and Apparatus. The stimulus presentation is illustrated in Figure 1. All stimuli were presented in white $\left(80 \mathrm{~cd} / \mathrm{m}^{2}\right)$ on the dark blue background $\left(2 \mathrm{~cd} / \mathrm{m}^{2}\right)$ of a computer screen and were viewed from a distance of approximately $50 \mathrm{~cm}$. The stimuli consisted of a fixation dot $\left(0.11^{\circ} \times 0.11^{\circ}\right.$ of visual angle $)$, a warning signal (an " 8 " with a height of $1.03^{\circ}$ and a width of $1.03^{\circ}$ of visual angle), a random noise mask $\left(1.26^{\circ} \times 1.26^{\circ}\right.$ of visual angle), and a target stimulus, which consisted either of 1 of 10 possible letters $\left(\mathrm{H}, \mathrm{E}, \mathrm{F}, \mathrm{P}, \mathrm{C}, \mathrm{U}, \mathrm{S}, \mathrm{O}, \mathrm{L}\right.$, or A; all $1.03^{\circ} \times 1.03^{\circ}$ of visual angle) or of a question mark $\left(0.57^{\circ} \times 0.34^{\circ}\right.$ of visual angle). To reduce spatial uncertainty, all stimuli were centered within a small quadratic frame $\left(2.3^{\circ} \times 2.3^{\circ}\right.$ of visual angle $)$ at the center of the monitor. Participants responded with the standard computer keyboard.

Procedure and Design. Each trial started with the presentation of the fixation dot, which was displayed for an interval of $(0.5+X)$ sec, where $X$ was a random variable that followed an exponential distribution with a mean of $1 \mathrm{sec}$. This random interval was introduced to emphasize the importance of the warning signal as a temporal reference for preparation (Müller-Gethmann et al., 2003). At the end of this interval, the fixation dot was replaced by the warning signal (" 8 ") for $200 \mathrm{msec}$. This numerical stimulus was employed as a warning to prevent any figural hints about the forthcoming imperative target. At offset of the warning signal, the fixation dot reappeared and then was replaced by the target after 600 or $2,200 \mathrm{msec}$. Thus, the foreperiod length between the onsets of the warning signal and the target was either 800 or $2,400 \mathrm{msec}$ for any given block of trials. The target was replaced by the mask, yielding target durations of 16,32 , or $48 \mathrm{msec}$. The mask was terminated after $800 \mathrm{msec}$, and a question mark indicated the onset of the response interval. The question mark remained on the screen until the response or, maximally, for $5 \mathrm{sec}$. The fixation dot then occurred for another $1,000 \mathrm{msec}$. The participants were asked to press the key on the computer keyboard that corresponded to the perceived letter and to respond as accurately as possible.

A single session lasted about $1 \mathrm{~h}$ and consisted of 18 blocks. Foreperiod length was kept constant within a block of 30 trials, whereas target duration was varied within each block. The foreperiod blocks alternated, and the order of the two foreperiod conditions was balanced across all participants. The first two blocks were considered practice and discarded from the data analysis. After each block, participants received summary feedback concerning their percentages of correct responses. No trial-by-trial accuracy feedback was given. The experiment factorially combined foreperiod length ( 800 or $2,400 \mathrm{msec})$, target duration $(16,32$, or $48 \mathrm{msec})$, and target type (10 letters).

\section{Results and Discussion}

A repeated measures ANOVA with the factors foreperiod length and target duration was conducted on percents correct (PCs) in the letter identification task. RTs were mea-

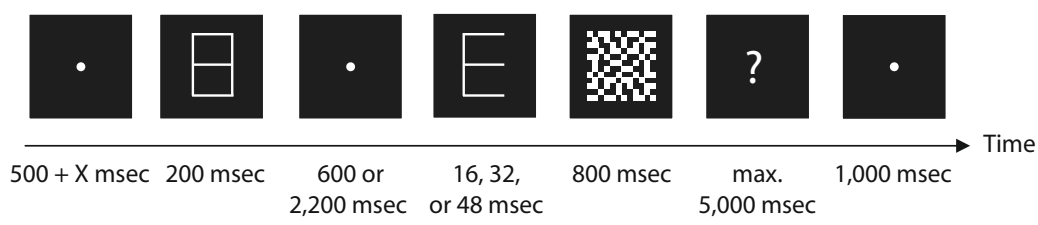

Figure 1. Time course of a single trial in Experiment 1. To reduce spatial uncertainty, all stimuli were presented within a small quadratic frame at the center of the monitor. Following the variable presentation time of the fixation dot, the visual warning signal (" 8 ") provided a cue for temporal preparation. After a blocked foreperiod of length 800 or $2,400 \mathrm{msec}$, the target occurred for a variable duration of 16,32 , or $48 \mathrm{msec}$. The target was displaced by a noise mask, consisting of a random dot pattern, for $800 \mathrm{msec}$. To avoid speeded responses in this experiment, a question mark provided the response cue. The participants had to identify the presented target letter. 
sured from onset of the response cue. RTs above and below two standard deviations $(S D s)$ from the mean of each experimental condition per participant were defined as outliers and rejected (4.8\%). An analysis was also performed on the mean RTs of correct responses. The $p$ values were, whenever appropriate, adjusted for violations of the sphericity assumption, using the Greenhouse-Geisser correction.

The results are summarized in Figure 2, which depicts PCs and mean RTs as functions of foreperiod length and target duration. As expected, and consistent with previous studies (e.g., Bachmann \& Allik, 1976), PC increased with increasing target durations $[F(2,38)=562.0, p<$ $\left..001, \eta_{\mathrm{p}}^{2}=.97\right]$. The most theoretically important finding, however, was that foreperiod length clearly influenced PC $\left[F(1,19)=14.1, p<.01, \eta_{\mathrm{p}}^{2}=.43\right]$; as temporal preparation decreased with foreperiod length, PC decreased. This result strongly suggests that temporal preparation enhances perceptual processing. The size of this foreperiod effect diminished as target duration was increased $\left[F(2,38)=6.8, p<.01, \eta_{\mathrm{p}}^{2}=.26\right]$, which might simply reflect a ceiling effect. Post hoc single comparisons per target duration revealed that the influence of foreperiod length was restricted to the shortest target duration $[F(1,19)=16.9, p<.001]$.

Although fast responses were excluded by the inclusion of the response interval, RTs increased with decreasing target duration $\left[F(2,38)=88.4, p<.001, \eta_{\mathrm{p}}^{2}=.82\right]$. This effect is consistent with one found in previous studies (e.g., Rolke \& Hofmann, 2007) that measured RTs under speed emphasis and most probably reflects increased task difficulty for short-lasting targets. In addition, there was a main effect of foreperiod length $[F(1,19)=48.3, p<$ $\left..001, \eta_{\mathrm{p}}^{2}=.72\right]$, and that factor also interacted with target duration $\left[F(2,38)=9.1, p<.01, \eta_{\mathrm{p}}^{2}=.32\right]$, indicating that the strength of the temporal preparation effect differed for the three target durations (for all post hoc single comparisons per target duration, $p \mathrm{~s}<.001)$. This effect of temporal preparation on RT was rather unexpected but might reflect a tendency of the participants to delay their responses when perceptual information was incomplete, because this hampers postperceptual decision processes. The present pattern of results, however, excludes the possibility of a trade-off between speed and accuracy, because RTs and accuracy were negatively correlated. Specifically, the increase of RTs was associated with a strong decrease in identification performance under low temporal preparation.

All in all, the present experiment confirms the hypothesis that temporal preparation enhances perceptual processing. Moreover, the results suggest that this perceptual influence is not restricted to specific and local stimulus properties but generalizes to the perceptual identification of letters. However, since the benefit of temporal preparation for identification performance was restricted to short-lasting targets, Experiment 2 was an attempt to replicate this effect.

\section{EXPERIMENT 2}

This experiment was conducted to replicate the benefit of temporal preparation on letter identification perfor-

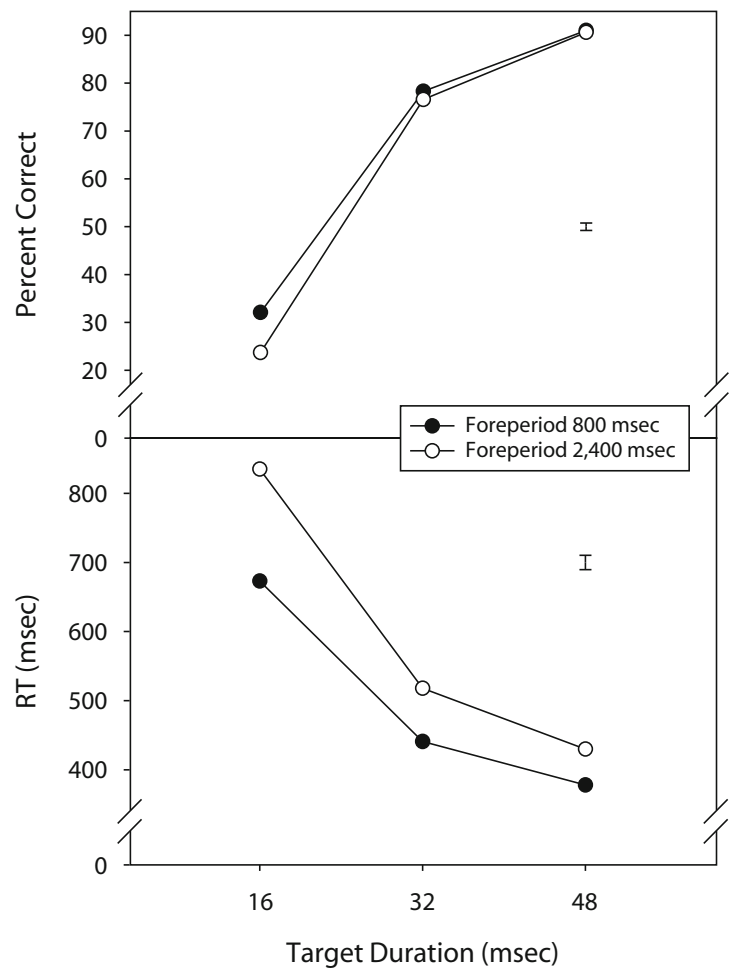

Figure 2. Results of Experiment 1: Percent correct identification performance and mean reaction times (RTs) of correct responses, as a function of foreperiod length $(800$ or $2,400 \mathrm{msec})$ and target duration $(16,32$, or $48 \mathrm{msec})$. Standard errors were computed from the pooled error terms of the corresponding ANOVA, according to a suggestion made by Loftus (2002).

mance. Moreover, its aim was to show that the effect of temporal preparation does not rely on the specific setup used in the previous experiment. For this reason, an alternative difficulty manipulation for the perceptual task was now realized. Specifically, the contrast of the target stimuli was varied instead of the target duration. It has been suggested that this contrast manipulation influences the early perceptual processing of a stimulus (Pashler \& Johnston, 1989; Sanders, 1980b) and probably changes the rate of the evidence accumulation process by slowing it down at low contrast levels (see, e.g., Hawkins, Shafto, \& Richardson, 1988). Thus, as with the target duration manipulation in Experiment 1, we expected that perceptual discrimination performance would improve in the backward-masking situation as contrast increased. In addition, and more crucially, we again expected temporal preparation to enhance perceptual letter identification.

\section{Method}

Participants. Another sample of 20 participants (1 man) were recruited from the same pool of students as in Experiment 1 and voluntarily took part in this experiment. Their mean age was 22.5 years, and they received course credit or a payment (€7/h).

Stimuli and Apparatus. All stimuli and stimulus parameters were identical to those in Experiment 1. To vary target contrast, the luminance of the letters was varied in three steps: They were pre- 
sented in white $\left(80 \mathrm{~cd} / \mathrm{m}^{2}\right)$, medium gray $\left(48 \mathrm{~cd} / \mathrm{m}^{2}\right)$, or dark gray $\left(24 \mathrm{~cd} / \mathrm{m}^{2}\right)$, yielding high, mid, and low contrast, respectively.

Procedure and Design. The sequence and timing of the stimuli during the course of a single trial were similar to those features in the first experiment, except that target letter duration was kept constant at $32 \mathrm{msec}$. As in Experiment 1, a single session consisted of 18 blocks ( 2 of them practice blocks) of 30 trials each. Target luminance was varied within a block of trials. This experiment factorially combined foreperiod length ( 800 or $2,400 \mathrm{msec}$ ), target contrast (high, mid, or low), and target type (10 letters).

\section{Results and Discussion}

As in Experiment 1, separate ANOVAs were performed, with the factors foreperiod length and target contrast, on the PCs and mean RTs of correct responses. Also as before, outlier trials were discarded (5.1\%).

The analysis of PC revealed results similar to those in Experiment 1 (see Figure 3). Because of the lower task difficulty with increasing target contrast, $\mathrm{PC}$ increased with that factor $\left[F(2,38)=65.0, p<.001, \eta_{\mathrm{p}}^{2}=.77\right]$. We found a main effect of foreperiod length $[F(1,19)=4.4$, $\left.p<.05, \eta_{\mathrm{p}}^{2}=.19\right]$ and an interaction of foreperiod length and target contrast $\left[F(2,38)=6.4, p<.01, \eta_{\mathrm{p}}^{2}=.25\right]$. As in Experiment 1, the influence of foreperiod length was most pronounced in the difficult condition. Post hoc comparisons revealed a beneficial effect of temporal prepara-

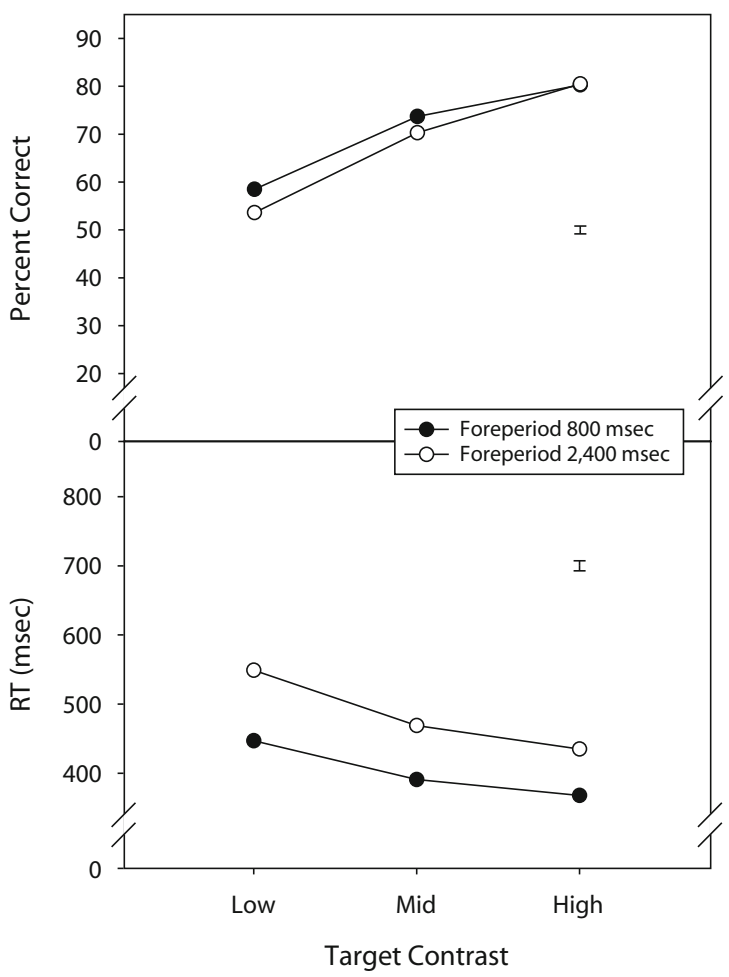

Figure 3. Results of Experiment 2: Percent correct identification performance and mean reaction times (RTs) of correct responses, as a function of foreperiod length $(800$ or $2,400 \mathrm{msec})$ and target contrast (low, mid, or high). Standard errors were computed from the pooled error terms of the corresponding ANOVA, according to a suggestion made by Loftus (2002). tion at low target contrast $[F(1,19)=10.1, p<.01]$, a weaker effect at mid contrast $[F(1,19)=4.4, p<.05]$, and no significant effect at high contrast $(F<1)$.

An ANOVA on RTs revealed that the manipulation of temporal preparation was once again effective, because mean RTs increased with foreperiod length $[F(1,19)=$ $\left.28.3, p<.001, \eta_{\mathrm{p}}^{2}=.60\right]$. In addition, mean RTs decreased with increasing contrast $[F(2,38)=19.8, p<$ $\left..001, \eta_{\mathrm{p}}^{2}=.51\right]$, but the factors did not interact $(p>$ .22). As in Experiment 1, the present pattern of results excluded a speed-accuracy trade-off to account for the better discrimination performance in the short-foreperiod condition. Taken together, the results again revealed enhanced identification performance in the short-foreperiod condition when task demands were high.

Although the results of these experiments were clearcut and seem to support the notion of a perceptual locus of temporal preparation, they are subject to an alternative explanation. ${ }^{2}$ According to this alternative, the different foreperiod durations might have produced differential mask effectiveness, which in turn could have influenced discrimination performance. More specifically, since the average display brightness (averaged over time) was higher when the foreperiod was short than when the foreperiod was long, the eyes were more dark-adapted in the long-foreperiod condition. It has been reported that a mask is more effective when the eyes are more dark-adapted (Breitmeyer, 1984; Purcell, Stewart, \& Stanovich, 1983). Thus, the different adaptation levels could easily have mimicked a temporal preparation effect of the foreperiod manipulation - that is, worse discrimination performance in the long- than in the short-foreperiod condition. Experiment 3 was therefore designed to exclude this alternative interpretation.

\section{EXPERIMENT 3}

This experiment was conducted to exclude the aboveoutlined dark adaptation explanation for the foreperiod effects in the previous experiments. To this end, dark adaptation differences between the foreperiod conditions were minimized by presenting a bright visual display throughout the trials. Thus, the target letters were presented in black against a light background. As in Experiment 2, there were three levels of target contrast. If the foreperiod effect obtained in Experiments 1 and 2 reflects an influence of dark adaptation, the foreperiod effect should disappear in this experiment.

\section{Method}

Participants. A group of 20 volunteers ( 5 men) from the same pool as in the previous experiments participated. Their mean age was 24.4 years, and they received course credit or a payment $(€ 7 / \mathrm{h})$.

Stimuli and Apparatus. All stimuli were identical to those in Experiment 2 . The stimuli were presented on a light gray background $\left(15.7 \mathrm{~cd} / \mathrm{m}^{2}\right)$. To vary target contrast, the luminance of the letters was varied in three steps: They were presented in black $\left(<1 \mathrm{~cd} / \mathrm{m}^{2}\right)$, medium gray $\left(2.8 \mathrm{~cd} / \mathrm{m}^{2}\right)$, or lighter gray $\left(7.2 \mathrm{~cd} / \mathrm{m}^{2}\right)$, yielding high, mid, and low contrast, respectively.

Procedure and Design. The sequence and timing of stimuli during the course of a single trial were similar to those aspects of Ex- 
periment 2 . The experiment factorially combined foreperiod length ( 800 or $2,400 \mathrm{msec}$ ), target contrast (high, mid, or low), and target type (10 letters).

\section{Results and Discussion}

As in the previous experiments, separate ANOVAs on the PCs and mean RTs of correct responses, with the factors foreperiod length and target contrast, were used to analyze the results. As before, outlier trials were discarded (5.1\%).

The results are summarized in Figure 4. The results of the analysis of PC mirrored those of the previous experiments. Because of the lower task difficulty with increasing target contrast, PC increased with that factor $[F(2,38)=$ $\left.210.7, p<.001, \eta_{\mathrm{p}}^{2}=.92\right]$. We found a main effect of foreperiod length $\left[F(1,19)=23.4, p<.001, \eta_{\mathrm{p}}^{2}=.55\right]$ and an interaction of foreperiod length and target contrast $\left[F(2,38)=4.5, p<.05, \eta_{\mathrm{p}}^{2}=.24\right]$. As revealed by post hoc comparisons, foreperiod length influenced PC most strongly in the low-target-contrast condition $[F(1,19)=22.1, p<.001]$, less in the mid-contrast condition $[F(1,19)=13.5, p<.01]$, and least of all at high contrast $[F(1,19)=9.0, p<.01]$.

An ANOVA revealed longer RTs as the foreperiod length increased $\left[F(1,19)=16.1, p<.001, \eta_{\mathrm{p}}^{2}=.46\right]$. In addition, mean RTs decreased with increasing contrast $\left[F(2,38)=16.8, p<.001, \eta_{\mathrm{p}}^{2}=.47\right]$, and the factors did not interact $(F<1)$. As in the previous experiments, the present pattern of results excludes a speed-accuracy trade-off. In sum, the results of this experiment replicate the pattern from the previous two experiments- that is, better discrimination performance in the short-foreperiod than in the long-foreperiod condition. Therefore, the light adaptation explanation must be ruled out, and differences in discrimination performance should be attributed to differences in temporal preparation.

\section{GENERAL DISCUSSION}

The present study addressed the question of whether the positive effect of temporal preparation on perceptual discrimination of single visual stimulus attributes (Klein \& Kerr, 1974; Lowe, 1967; Rolke \& Hofmann, 2007) generalizes to the perceptual identification of letters. As in the study of Rolke and Hofmann, the quality of perceptual processing was manipulated by a backward-masking manipulation. The results of the present experiments clearly show that temporal preparation enhances identification performance of letters. This identification benefit was most pronounced when perceptual task demands were high - that is, at short stimulus durations and low contrast levels. This pattern of results strengthens Rolke and Hofmann's conclusion that temporal preparation exerts its effect at a perceptual level of signal processing. Furthermore, the results show that this perceptual benefit of temporal preparation is not restricted to the processing of single stimulus features that require high spatial resolution, but generalizes to the identification and categorization of letters at higher perceptual levels.

The benefit of temporal preparation for perceptual processing can be explained by the accumulation model pro- posed by Rolke and Hofmann (2007). According to this account, temporal preparation accelerates the onset of the accumulation process in the short-foreperiod condition (see also Grosjean, Rosenbaum, \& Elsinger, 2001, and Simon \& Slaviero, 1975, for similar suggestions). In the case of a backward-masking paradigm, the identification of a stimulus critically depends on the effective processing time, because the backward mask interrupts the processing of the target and erases its visual memory trace (Kahneman, 1968; Sperling, 1963). Therefore, if the time interval of target processing is prolonged by earlier onset of the accumulation process, the perceptual identification of the stimulus is based on more accumulated evidence toward a decision criterion value, and as a consequence, discrimination performance improves. This early onset hypothesis predicts that enhanced identification performance should not be restricted to the processing of single stimulus attributes, which relies on high temporal resolution. In contrast, all perceptual processing stages should profit when temporal preparation is high, and thus the hypothesis can account for the present results.

Additional support for the early onset hypothesis comes from temporal discrimination research. For example, Grondin and Rammsayer (2003; see also Mo \& George, 1977) investigated, in a series of experiments, whether

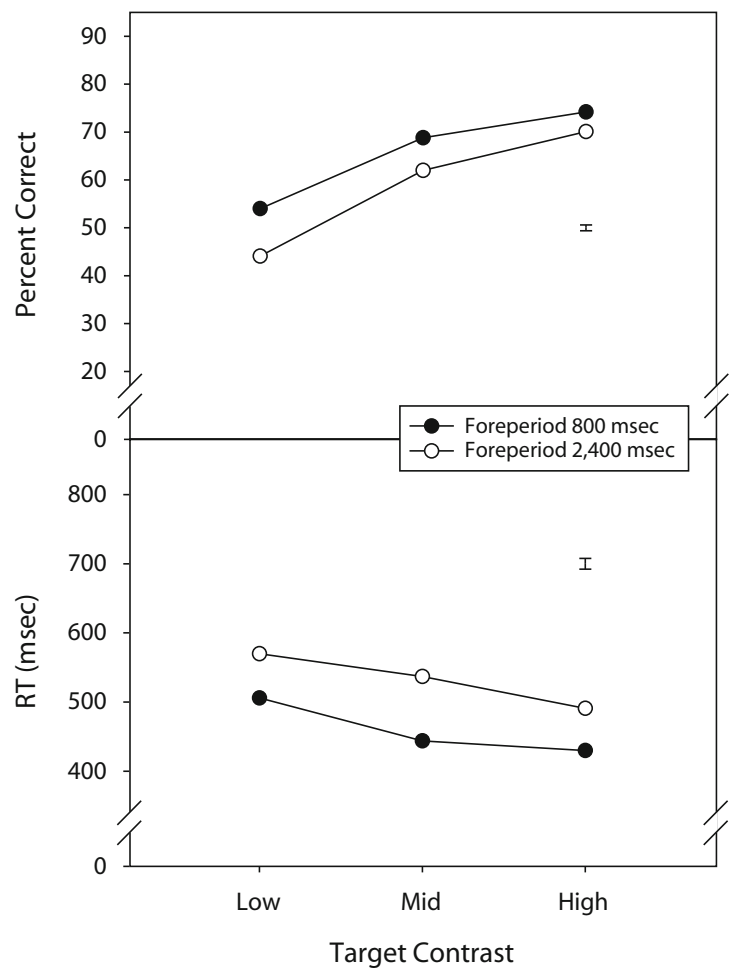

Figure 4. Results of Experiment 3: Percent correct identification performance and mean reaction times (RTs) of correct responses, as a function of foreperiod length $(800$ or $2,400 \mathrm{msec})$ and target contrast (low, mid, or high). Standard errors were computed from the pooled error terms of the corresponding ANOVA, according to a suggestion made by Loftus (2002). 
temporal preparation affects the perceived duration of empty temporal intervals delimited by auditory or visual markers. With high temporal preparation, intervals were judged to be longer than with low temporal preparation. Just this pattern of results would be expected if one assumed that temporal preparation leads to earlier detection of critical perceptual events. Specifically, the first marker of the interval might be detected more quickly when participants are temporally prepared. Since the influence of temporal preparation might be reduced for the second marker, this would lead to the impression of relatively long empty intervals. ${ }^{3}$ Furthermore, two recent studies (Bausenhart, Rolke, \& Ulrich, in press; Correa, Sanabria, Spence, Tudela, \& Lupiáñez, 2006) assessed the influence of temporal preparation on the temporal resolution of visual stimulus processing. In these studies, participants were required to indicate whether one stimulus occurred temporally before another (a temporal order judgment, or TOJ). When the moment of stimulus occurrence could be predicted accurately, performance in the TOJ task improved. These results suggest that temporal preparation enhances the temporal resolution of the visual system. Moreover, they are compatible with the early onset hypothesis, if one assumes that an earlier start of the accumulation process for the first stimulus causes the beneficial TOJ performance. Therefore, along with the backwardmasking study of Rolke and Hofmann (2007) and the present study, several lines of evidence provide support for the early onset hypothesis of temporal preparation.

The present finding of a perceptual influence of temporal preparation is also consistent with recent research on orienting attention in time. For example, Correa, Lupiáñez, and Tudela (2005) used a temporal analogue of a spatial-cuing procedure (Posner, Snyder, \& Davidson, 1980 ) in a temporal-cuing paradigm to induce temporal preparation (see, e.g., Coull \& Nobre, 1998). On each trial, symbolic cues indicated whether a visual target was likely to appear early or late among a rapidly presented stream of distractor stimuli. Detection performance for the targets, which were presented at the expected time interval, was higher than detection performance for targets that occurred at an unexpected time interval. This result indicates that attentional preparation in time modulates processing at a perceptual level.

Finally, converging evidence for a perceptual influence of temporally oriented attention comes from electrophysiological studies. Correa, Lupiáñez, Madrid, and Tudela (2006; see also Lange, Rösler, \& Röder, 2003) employed a letter discrimination task and investigated the influence of temporally oriented attention on visual perceptual processing. In addition to a modulation of later ERP components, attended target letters evoked a larger P1 component than did unattended target letters. Thus, the authors stated that temporal attention enhances perceptual processing. To explain the fact that several studies failed to find any modulation of early ERP components, Correa, Lupiáñez, et al. (2006) assumed that the influence of temporal attention on stimulus processing might depend on the task requirements. Specifically, they suggested that early visual processing might be modulated by temporal attention only when perceptually demanding tasks are used. Although the relationship is still unclear between the mechanisms evoked by orienting attention in time with a cue and by providing temporal preparation within a foreperiod paradigm, the studies above agree with the present conclusion that temporal preparation improves perceptual stimulus processing under high perceptual processing demands.

The conclusion of a perceptual effect, however, does not mean that temporal preparation exclusively influences perceptual processing stages. For example, the data of some other additive-factor method studies (e.g., Sanders, 1980a, 1998) have shown that instructed muscle tension modulates the foreperiod effect on RTs, and several other studies have reported an effect of temporal preparation on the correlates of motor processes (e.g., Brunia \& van Boxtel, 2000; Mattes \& Ulrich, 1997; Tandonnet et al., 2006). Furthermore, the above-mentioned chronophysiological studies and the PRP study as well do not conflict with the possibility that response selection is affected by temporal preparation. Therefore, although the present results argue for a perceptual locus of temporal preparation, they do not deny the possibility that temporal preparation might also influence response preparation and motor execution processes.

In conclusion, the present study clearly shows that temporal preparation facilitates perceptual analysis in perceptually highly demanding conditions. According to the proposed early onset hypothesis, this benefit of temporal preparation results most probably by accelerating the onset of the accumulation process that leads to a more stable perceptual representation of the stimulus. This perceptual facilitation is not restricted to low-level perceptual processing, but generalizes to the level of letter identification, which necessitates the extraction and combination of several stimulus features.

\section{AUTHOR NOTE}

This study was supported by Grant RO 3034/2-1 from the German Research Foundation (DFG). I thank Rolf Ulrich for helpful comments and Mareike Schmid and Matthias Walker for their help in data acquisition. I also thank Jeff Miller, Sander Los, and Simon Grondin for helpful comments on previous drafts of the manuscript. Correspondence should be sent to B. Rolke, Cognitive and Biological Psychology, University of Tübingen, Friedrichstrasse 21, 72072 Tübingen, Germany (e-mail: bettina.rolke@uni-tuebingen.de).

\section{REFERENCES}

Bachmann, T., \& Allik, J. (1976). Integration and interruption in the masking of form by form. Perception, 5, 79-97.

Bausenhart, K. M., Rolke, B., Hackley, S. A., \& Ulrich, R. (2006). The locus of temporal preparation effects: Evidence from the psychological refractory period paradigm. Psychonomic Bulletin \& Review, 13, 536-542.

Bausenhart, K. M., Rolke, B., \& Ulrich, R. (2007). Knowing when to hear aids what to hear. Quarterly Journal of Experimental Psychology, 60, 1610-1615.

Bausenhart, K. M., Rolke, B., \& Ulrich, R. (in press). Temporal preparation improves temporal resolution: Evidence from constant foreperiods. Perception \& Psychophysics.

Bevan, W., Hardesty, D. L., \& Avant, L. L. (1965). Response latency with constant and variable interval schedules. Perceptual \& Motor Skills, 20, 969-972. 
BREITMEYER, B. G. (1984). Visual masking: An integrative approach. Oxford: Oxford University Press, Clarendon Press.

Brunia, C. H. M., \& van BoXtel, G. J. M. (2000). Motor preparation. In J. T. Cacioppo, L. G. Tassinary, \& G. G. Berntson (Eds.), Handbook of psychophysiology (2nd ed., pp. 507-532). Cambridge: Cambridge University Press.

Carrasco, M., Williams, P. E., \& Yeshurun, Y. (2002). Covert attention increases spatial resolution with or without masks: Support for signal enhancement. Journal of Vision, 2, 467-479.

COHEN, A., \& IvrY, R. (1989). Illusory conjunctions inside and outside the focus of attention. Journal of Experimental Psychology: Human Perception \& Performance, 15, 650-663.

Correa, Á., Lupiá ÑEZ, J., \& Tudela, P. (2005). Attentional preparation based on temporal expectancy modulates processing at the perceptual level. Psychonomic Bulletin \& Review, 12, 328-334.

Correa, Á., Lupiáñez, J., Madrid, E., \& Tudela, P. (2006). Temporal attention enhances early visual processing: A review and new evidence from event-related potentials. Brain Research, 1076, 116-128.

Correa, Á., Sanabria, D., Spence, C., Tudela, P., \& Lupiáñez, J. (2006). Selective temporal attention enhances the temporal resolution of visual perception: Evidence from a temporal order judgment task. Brain Research, 1070, 202-205

Coull, J. T., \& Nobre, A. C. (1998). Where and when to pay attention: The neural systems for directing attention to spatial locations and to time intervals as revealed by both PET and fMRI. Journal of Neuroscience, 18, 7426-7435.

DRAZIN, D. H. (1961). Effects of foreperiod, foreperiod variability, and probability of stimulus occurrence on simple reaction time. Journal of Experimental Psychology, 62, 43-50.

Frowein, H. W., \& SANDERs, A. F. (1978). Effects of visual stimulus degradation, S-R compatibility, and foreperiod duration on choice reaction time and movement time. Bulletin of the Psychonomic Society, 12, 106-108.

Grondin, S., \& RAmmsaYer, T. (2003). Variable foreperiods and temporal discrimination. Quarterly Journal of Experimental Psychology, 56A, 731-765

Grosjean, M., Rosenbaum, D. A., \& Elsinger, C. (2001). Timing and reaction time. Journal of Experimental Psychology: General, 130, 256-272.

Hackley, S. A., Schankin, A., Wohlschläger, A., \& Wascher, E. (2007). Localization of temporal preparation effects via trisected reaction time. Psychophysiology, 44, 334-338.

Hackley, S. A., \& Valle-Inclán, F. (1998). Automatic alerting does not speed up late motoric processes in a reaction-time task. Nature, 391, 786-788.

HaCKLEY, S. A., \& VALLE-INCLÁN, F. (1999). Accessory stimulus effects on response selection: Does arousal speed decision making? Journal of Cognitive Neuroscience, 11, 321-329.

HACKLEY, S. A., \& VALLE-INCLÁN, F. (2003). Which stages of processing are speeded by a warning signal? Biological Psychology, 64, 27-45.

Hasbrouce, T., Kaneko, H., Akamatsu, M., \& Possamaï, C.-A. (1999). The time-course of preparatory spinal and cortico-spinal inhibition: An H-reflex and transcranial magnetic stimulation study in man. Experimental Brain Research, 124, 33-41.

Hawkins, H. L., Shafto, M. G., \& Richardson, K. (1988). Effects of target luminance and cue validity on the latency of visual detection. Perception \& Psychophysics, 44, 484-492.

Howarth, C. I., \& Treisman, M. (1961). Lowering of an auditory threshold by a near threshold warning signal. Quarterly Journal of Experimental Psychology, 13, 12-18.

KaHNEMAN, D. (1968). Method, findings, and theory in studies of visual masking. Psychological Bulletin, 70, 404-425.

KLEIN, R., \& KerR, B. (1974). Visual signal detection and the locus of foreperiod effects. Memory \& Cognition, 2, 431-435.

KLEMMER, E. T. (1956). Time uncertainty in simple reaction time. Journal of Experimental Psychology, 51, 179-184.

LANGE, K., RÖsLER, F., \& RöDER, B. (2003). Early processing stages are modulated when auditory stimuli are presented at an attended moment in time: An event-related potential study. Psychophysiology, 40, 806-817.

LofTUs, G. R. (2002). Analysis, interpretation, and visual presentation of experimental data. In H. Pashler (Ed.), Stevens' handbook of experimental psychology: Vol. 4. Methodology in experimental psychology (3rd ed., pp. 339-390). Hoboken, NJ: Wiley.
Los, S. A., KNol, D. L., \& Boers, R. M. (2001). The foreperiod effect revisited: Conditioning as a basis for nonspecific preparation. Acta Psychologica, 106, 121-145.

Los, S. A., \& Van Den Heuvel, C. E. (2001). Intentional and unintentional contributions to nonspecific preparation during reaction time foreperiods. Journal of Experimental Psychology: Human Perception \& Performance, 27, 370-386.

Loveless, N. E. (1973). The contingent negative variation related to preparatory set in a reaction time situation with variable foreperiod. Electroencephalography \& Clinical Neurophysiology, 35, 369-374.

LovelEss, N. E. (1975). The effect of warning interval on signal detection and event-related slow potentials of the brain. Perception \& Psychophysics, 17, 565-570.

Lowe, G. (1967). Interval of time uncertainty in visual detection. Perception \& Psychophysics, 2, 278-280.

MARR, D. (1982). Vision: A computational investigation into the human representation and processing of visual information. San Francisco: Freeman

Mattes, S., \& UlRich, R. (1997). Response force is sensitive to the temporal uncertainty of response stimuli. Perception \& Psychophysics, 59, 1089-1097.

MiLleR, J., \& Reynolds, A. (2003). The locus of redundant-targets and nontargets effects: Evidence from the psychological refractory period paradigm. Journal for Experimental Psychology: Human Perception \& Performance, 29, 1126-1142.

Mo, S. S., \& George, E. J. (1977). Foreperiod effect on time estimation and simple reaction time. Acta Psychologica, 41, 47-59.

Müller-Gethmann, H., Ulrich, R., \& Rinkenauer, G. (2003). Locus of the effect of temporal preparation: Evidence from the lateralized readiness potential. Psychophysiology, 40, 597-611.

NiEMI, P. (1979). Stimulus intensity effects on auditory and visual reaction processes. Acta Psychologica, 43, 299-312.

Niemi, P., \& Lehtonen, E. (1982). Foreperiod and visual stimulus intensity: A reappraisal. Acta Psychologica, 50, 73-82.

NiEMI, P., \& NäÄTÄNEN, R. (1981). Foreperiod and simple reaction time. Psychological Bulletin, 89, 133-162.

Pashler, H., \& Johnston, J. C. (1989). Chronometric evidence for central postponement in temporally overlapping tasks. Quarterly Journal of Experimental Psychology, 41A, 19-45.

Pashler, H., \& Johnston, J. C. (1998). Attentional limitations in dualtask performance. In H. Pashler (Ed.), Attention (pp. 155-189). Hove, U.K.: Psychology Press.

Posner, M. I., Snyder, C. R., \& Davidson, B. J. (1980). Attention and the detection of signals. Journal of Experimental Psychology: General, 109, 160-174.

Prinzmetal, W., Presti, D. E., \& Posner, M. I. (1986). Does attention affect visual feature integration? Journal of Experimental Psychology: Human Perception \& Performance, 12, 361-369.

Purcell, D. G., Stewart, A. L., \& Stanovich, K. E. (1983). Another look at semantic priming without awareness. Perception \& Psychophysics, 34, 65-71.

RaAb, D., Fehrer, E., \& Hershenson, M. (1961). Visual reaction time and the Broca-Sulzer phenomenon. Journal of Experimental Psychology, 61, 193-199.

RoDWAY, P. (2005). The modality shift effect and the effectiveness of warning signals in different modalities. Acta Psychologica, 120, 199-226.

Rolke, B., \& Hofmann, P. (2007). Temporal uncertainty degrades perceptual processing. Psychonomic Bulletin \& Review, 14, 522-526.

SANDERS, A. F. (1980a). Some effects of instructed muscle tension on choice reaction time and movement time. In R. S. Nickerson (Ed.), Attention and performance VIII (pp. 59-74). Hillsdale, NJ: Erlbaum.

SANDERS, A. F. (1980b). Stage analysis of reaction processes. In G. E. Stelmach \& J. Requin (Eds.), Tutorials in motor behavior (pp. 331354). Amsterdam: North-Holland.

SANDERS, A. F. (1998). Elements of human performance: Reaction processes and attention in human skill. Mahwah, NJ: Erlbaum.

Sanders, A. F., \& Wertheim, A. H. (1973). The relation between physical stimulus properties and the effect of foreperiod duration on reaction time. Quarterly Journal of Experimental Psychology, 25, 201-206.

Simon, J. R., \& Staviero, D. P. (1975). Differential effects of a foreperiod countdown procedure on simple and choice reaction time. Journal of Motor Behavior, 7, 9-14. 
Smith, P. L., \& Wolfgang, B. J. (2004). The attentional dynamics of masked detection. Journal of Experimental Psychology: Human Perception \& Performance, 30, 119-136.

SMulders, F. T. Y. (1993). The selectivity of age effects on information processing: Response times and electrophysiology. Unpublished doctoral dissertation, University of Amsterdam.

Sperling, G. (1963). A model for visual memory tasks. Human Factors, $\mathbf{5}, 19-31$.

SPIJKERS, W. A. (1990). The relation between response-specificity, S-R compatibility, foreperiod duration and muscle-tension in a target aiming task. Acta Psychologica, 75, 261-277.

SternberG, S. (2001). Separate modifiability, mental modules, and the use of pure and composite measures to reveal them. Acta Psychologica, 106, 147-246.

Tandonnet, C., Burle, B., Vidal, F., \& Hasbroucq, T. (2003). The influence of time preparation on motor processes assessed by surface Laplacian estimation. Clinical Neurophysiology, 114, 2376-2384.

Tandonnet, C., Burle, B., Vidal, F., \& HasbroucQ, T. (2006). Knowing when to respond and the efficiency of the cortical motor command: A Laplacian ERP study. Brain Research, 1109, 158-163.

TeICHNER, W. H. (1954). Recent studies of simple reaction time. Psychological Bulletin, 51, 128-149.

Treisman, A. M., \& Gelade, G. (1980). A feature-integration theory of attention. Cognitive Psychology, 12, 97-136.

Treisman, M., \& Howarth, C. I. (1959). Changes in threshold level produced by a signal preceding or following the threshold stimulus. Quarterly Journal of Experimental Psychology, 11, 129-142.

TuRVEY, M. T. (1973). On peripheral and central processes in vision: Inferences from an information-processing analysis of masking with pattern stimuli. Psychological Review, 80, 1-52.

VAN der Lubbe, R. H. J., Los, S. A., JAŚKowski, P., \& Verleger, R. (2004). Being prepared on time: On the importance of the previ- ous foreperiod to current preparation, as reflected in speed, force and preparation-related brain potentials. Acta Psychologica, 116, 245-262.

Woodrow, H. (1914). The effect upon reaction time of variation in the preparatory interval. In J. Angell, H. Warren, J. Watson, \& S. Franz (Eds.), The psychological monographs (pp. 16-65). Princeton, NJ: Psychological Review Co.

YESHURUN, Y. (2004). Isoluminant stimuli and red background attenuate the effects of transient spatial attention on temporal resolution. Vision Research, 44, 1375-1387.

Yeshurun, Y., \& CARrasco, M. (1999). Spatial attention improves performance in spatial resolution tasks. Vision Research, 39, 293-306.

Yeshurun, Y., \& LeVy, L. (2003). Transient spatial attention degrades temporal resolution. Psychological Science, 14, 225-231.

\section{NOTES}

1. The term premotoric in the context of the present article refers to perceptual and central processing stages. Thus, this term includes motor preparation processes such as response selection, but excludes response execution.

2. I thank Jeff Miller for suggesting this alternative.

3. Grondin and Rammsayer (2003) and Mo and George (1977) obtained this effect of temporal preparation in a variable-foreperiod condition - that is, the durations of the foreperiod varied across the trials of a single block rather than from block to block, as in the present study. In a variable-foreperiod paradigm, temporal preparation is assumed to increase as the foreperiod ages, since the likelihood of stimulus delivery grows as the foreperiod increases.

(Manuscript received July 20, 2007; revision accepted for publication April 24, 2008.) 